\title{
Male-Female Earnings Differentials: A Critical Reappraisal*
}

\author{
WALTER BLOCK
}

Fraser Institute

\author{
WALTER WILLIAMS \\ George Mason University
}

In the May 1978 issue of The Canadian Journal of Economics, Roberta Robb attributed between 58.9 per cent (standardized for occupation and industry) and 75.4 per cent (not standardized) of the male-female Ontario earnings differential in 1971 to sexual discrimination. We should like to point out several flaws in the analysis.

First, Robb seems to miss the point of the alternative hypothesis to sexual discrimination. That hypothesis is that marriage - and its asymmetrical effects on male and female career efforts, due to asymmetrical domestic responsibilities and commitments - means qualitatively different performance levels by men and women who are married, or have been married. Never married women should be compared to never married men, not all men [See Robb (1978, p. 357), Tables 3 and 4.] Age, even if it quantitatively captures work experience, does not get at this qualitative point. These are more than quibbles; they make an empirical difference in the results. Data cited by Sowell (1975) in Affirmative Action Reconsidered showed that "never married" academic women receive higher pay than "never married" academic men. Other studies cited there also detail the asymmetry of domestic responsibilities and the greater frequency of female subordination of individual career goals to that of the husband's career - notably in locating where he has the best opportunity, even if that is not where her best opportunities exist. In short, the effect of marriage on a woman is much more than a difference in labour force participation rates or continuity of employment. Comparing all men to never married women seems to be an incredible procedure - however widespread - when marriage has opposite effects on the quality of inputs into a career, freeing the man's time and absorbing the woman's. Surveys show men and women themselves saying this, and we know of no serious reason to doubt it.

Secondly, Robb's estimates are not a reliable measure of the presence or absence of tastes that may influence practices, for while the experimenter may have reliable information on the productivity of a particular employee, there is no reason at all to believe that the employer is similarly blessed. Even if all the

\footnotetext{
*The authors would like to thank Thomas Sowell of U.C.L.A. and Michael Walker of The Fraser Institute for helpful comments.
} 
applicants have identical credentials, we cannot expect employers to perceive these credentials as equally creditable, even in a non-sexist world. ${ }^{1}$

Different people for different decisions choose to acquire different amounts of information prior to acting. There is a criteria used to determine the amount of information an individual will rationally invest in prior to making a decision: people search for information up to the point where the added cost of another unit of knowledge is just offset by the expected benefits that will be derived from that additional unit.

It is crucial to understand that both costs and benefits from an additional unit of information vary from individual to individual. On the cost side, economic actors differ in their ability or efficacy in the collection and processing of information. On the benefit side, people differ in their risk aversion and in their subjective evaluation of an additional unit of information, i.e. the marginal rate of substitution between the product of information (increased probability of making the "correct" decision) and all other goods is not the same for all individuals. ${ }^{2}$

Therefore, the conceptual experiment suggested by Robb cannot be viewed as a reliable measure of the absence or presence of sexist tastes. In such an experiment, it is important for the experimentor to recognize that while she may have reliable information that workers are undifferentiated except by sex, the employer may not. Even employers with sex neutral tastes have to perceive that certain skills are distributed randomly if they are to select employees randomly. To the extent that skills are not distributed randomly, sexual attributes may be employed with some success as an indicator of the productivity level sought by the firm. Using sex as a "proxy" for some other characteristic is consistent with preferences that are malevolent, benevolent or indifferent toward a particular sex.

The suggestion that sexual attributes will be used in worker selection or payment implies nothing about employer sexual tastes. It does imply scarcity. Employers cannot be sure of the productivity of a worker before he is hired; moreover, the worker's productivity may not be readily discernible after he is hired.The process of hiring uses resources. In addition, the trial period is costly; it, too, uses the resources of the firm in the form of added supervision monitoring and materials. Employers have incentive to economize on all of these costs.

A third difficulty is that Robb attributes to sexual discrimination all the male-female earnings differentiation that cannot be accounted for by her other independent variables (age, education, occupation, industry, hours worked,

\footnotetext{
'A similar argument can be made about the analysis of racial differences, in other areas of economic life. In the poor-pay-more issue of the 1960s, experimentors conducted tests to determine whether there was racial discrimination in the sale of customer durables and credit terms by having couples shop for credit who differed only by race. See Williams (1973).

${ }^{2}$ Given this line of reasoning, prejudiced behaviour cannot have normative content. Most often the discrimination literature prejudiced behavior is used pejoratively in reference to individuals whose optimal amount of information is relatively small (in the opinion of the author). But we have seen that the quantity decision is individual, thus there can be no meaning attached to "socially" optimal quantities of information for a decision.
} 
weeks worked, training, marital status) but these by no means exhaust the explanatory possibilities. Other phenomena which might possibly account for the male-female earnings differential would include intelligence, motivation, determination, cheerfulness, ability to work well with others, etc. True, these are hardly amenable to statistical manipulation. But the time is long past when an analysis can be considered methodologically sound that considers only what can be (easily) measured, and attributes the remaining differential to one such variable: discrimination. At the very best, Robb's conclusion must be modified so as to attribute the male-female earnings differential left unexplained by her other independent variables to discrimination as well as these other "non measurable" phenomena.

But let us make the heroic ceteris paribus, assumption that males and females do not differ with regard to any conditions such as intelligence, motivation, etc. Let us further assume that no tastes whatsoever for sexual discrimination exist in the society. Would Robb's independent variables fully explain the Ontario male-female earnings differentials of 1971 even then? They would only do so under conditions of full and perfect general equilibrium in the economy.

The fourth difficulty with the Robb thesis, then, is that it implicitly assumes the existence of equilibrium. But the cessation of the market process is only an ideal construct, a heuristic device. Unless Robb believes that this can apply in the real world, ${ }^{3}$ she cannot, unambiguously attribute any unexplained differential to sexual discrimination. Some of it at least, must be blamed on the fact that the economy of Ontario in 1971 was in disequilibrium.

\footnotetext{
${ }^{3}$ Among the paradoxical implications of full equilibrium is that money could not exist (See Von Mises (1966, p. 417), nor could profits (See Kirzner (1973, p. 1, 4, 13)).
} 


\section{REFERENCES}

Kirzner, Israel M. (1973) Competition and Entrepreneurship (Chicago: University of Chicago Press). Robb, Roberta Edgecombe (1978) "Earnings Differentials Between Males and Females in Ontario, 1971," The Canadian Journal of Economics, pp. 350-59.

Sowell, Thomas (1975) Affirmative Action Reconsidered (Washington, D.C.: American Enterprise Institute for Public Policy Research).

Von Mises, Ludwig (1966) Human Action (Chicago: Henry Regnery, third revised edition).

Williams, Walter E. (1973) "Why the Poor Pay More: An Alternative Explanation," Social Science Quarterly, pp. 375-79. 